\title{
The place of intertrochanteric osteotomy in the treatment of idiopathic necrosis of the head of the femur
}

\author{
J. Cañadell, L. Aguilella, J. R. Azcárate, and J. R. Valenti
}

Department of Orthopaedic Surgery and Traumatology, University Clinic of Navarra, 31008 Pamplona, Spain

\section{SUMMARY}

The authors present their experience of the use of intertrochanteric osteotomy for the treatment of idiopathic necrosis of the head of the femur. The results obtained from 102 osteotomies performed on 81 patients with the disease are analysed. The mean followup is 4.2 years. The results show a statistically significant clinical improvement after operation. Patients presenting with Ficat and Arlet Stage II involvement fared much better than those with more severe changes. Better results were also seen in those with a necrosis angle of less than $200^{\circ}$. No radiological improvement was seen although a high percentage showed no deterioration. The choice of treatment for the condition is discussed in the light of these results.

\section{RÉSUMÉ}

Les auteurs présentent leur expérience de l'ostéotomie intertrochantérienne dans le traitement de la nécrose idiopathique de la tête fémorale. Ils analysent les résultats obtenus dans 102 ostéotomies, pratiquées sur 81 malades, avec un recul de 4.1 ans. Une amélioration clinique statistiquement significative a été observée après l'opération, spécialement dans les cas vus au stade II de Ficat et Arlet (91\% des malades sont satisfaits). L'influence de l'angle de nécrose est également démontrée, les meilleurs résultats ayant été obtenus lorsque cet angle est inférieur à $200^{\circ}$. Il n'y a pas d'amélioration radiologique, main une stabilisation de l'évolution dans un grand nombre de cas. À la lumière des résultats obtenus, les auteurs exposent leurs indications thérapeutiques dans le traitement de l'ostéonécrose de la tête fémorale.

\section{KEY WORDS}

Femur, Head, Idiopathic necrosis, Intertrochanteric osteotomy 


\section{INTRODUCTION}

A number of methods of treatment for idiopathic necrosis of the head of the femur, based on the characteristics of the lesion, have been reported previously $[4,5,6,8,11$, $12,14,16,17,18,20,22]$. However, the choice of treatment for relatively young patients presenting with intermediate grade disease is still uncertain.

Since 1974 we have been using intertrochanteric osteotomy as the method of choice in the treatment of less severely affected hips, showing either early radiological signs or collapse of the contour of the head and degenerative changes.

This paper presents the results of our experience in an area with a high incidence of this condition [19]. The results have been assessed to try to determine the indications for intertrochanteric osteotomy for idiopathic necrosis of the femoral head and the place of the operation in the treatment of the disease.

\section{MATERIAL AND METHODS}

One hundred and two osteotomies were performed on 81 patients diagnosed as having idiopathic necrosis of the femoral head between 1974 and 1982.

There were 78 men and 3 women, and $46 \%$ had bilateral disease. The age range was from 25 to 60 years (mean 41.5 years) (Fig. 1). Follow-up was from one.to ten years (mean 4.2 years).

\section{Technique}

Ninety one flexion-valgus osteotomies and 11 flexion-varus osteotomies were performed. The angle of the wedge resection varied from $20^{\circ}$ to $30^{\circ}$ according to the type and extent of correction thought necessary because of the site and size of the necrotic focus. In most osteotomies the distal fragment was displaced to try to preserve the mechanical axis of the limb. All osteotomies were stabilised using either $90^{\circ}$ or $130^{\circ}$ $\mathrm{AO}$ angled plates or $130^{\circ} \mathrm{CUN}$ plates [13].

\section{Assessment of clinical results}

Pain, movement and gait were assessed before operation and at intervals of one year after operation using the Charnley modification of the six-point scale of Merle d'Aubigne [26]. The scores for pain and gait were then doubled and added to the movement score to give an overall value between 5-30 according to the method of Willert [26]. The clinical result of each operation was classified according to the final score achieved as, very good (28-30), good (25-27), acceptable (22-24) or bad (21 or less). The patients' opinions of their result were recorded as "unsatisfactory", "satisfactory" or "very satisfactory". 


\section{Assessment of statistical significance}

The scores before and after operation for pain, movement, gait and the overall assessment were compared using the t-test for paired values. Other tests of significance were made using the $\chi^{2}$-test. All calculations were made using BMDP programmes [7]. Complications and revision operations were also recorded.

\section{Radiological assessment}

This was done using the Ficat and Arlet scale [8]. The extent of the necrotic focus was determined by measurement of the angle of the lesion in both AP and axial views, as previously reported by others $[15,25]$. In some cases AP tangential views, either with the hip flexed to $45^{\circ}$ (antero-superior segment), or with the postero-superior focus at $30^{\circ}$ (postero-superior segment) were also used. The percentage of femoral head affected was calculated using an HP-9864A digitiser linked to an HP-9830A microcomputer.

Post-operatively we looked for changes in the density of the necrotic area, the congruity of the joint surfaces, the size of the joint space and the contour of the head of the femur. From these observations we recognised four types of change, regeneration, stabilisation, moderate deterioration and severe deterioration [1].

\section{RESULTS}

\section{Clinical grading}

Using the Willert scale, hips were graded very good in $14 \%$, good in $20 \%$, acceptable in $25 \%$ and bad in $41 \%$. A clinically satisfactory result was achieved in 59\%. The improvement is highly significant $(\mathrm{p}<0.001)$. Sixty one percent of patients were satisfied $(45 \%)$ or very satisfied $(16 \%)$, and $39 \%$ thought the result unsatisfactory.

\section{Pain}

Before operation 18\% patients scored between 4-6 (slight pain, mild discomfort, no pain respectively) against $65 \%$ at final assessment. The improvement is very significant $(\mathrm{p}<0.001)$.

\section{Movements}

The final score showed a significant fall in range of movement $(\mathrm{p}<0.01)$.

\section{Gait}

Scores generally improved but the difference was not statistically significant. The clinical results of the series are recorded in Fig. 2. 


\section{Radiological results}

Before operation using the Ficat and Arlet scale $22 \%$ of hips were graded Stage II, $56 \%$ Stage III and $22 \%$ Stage IV. Necrosis angles varied from $158^{\circ}$ to $318^{\circ}$ (average $214^{\circ} \pm$ $30^{\circ}$ ); the distribution is shown in Fig. 3. The percentage of femoral head surface involved was from $12 \%$ to $96 \%$, averaging $44 \% \pm 13 \%$.

The overall clinical scores following osteotomy, grouped according to the radiological stage before operation, are shown in Table 1 . The results were acceptable or better in $91 \%$ of Stage II hips, in $56 \%$ of Stage III and in $32 \%$ of Stage IV. This association is very significant $(p<0.001)$. Table 2 shows the level of patient satisfaction with the operation by radiological group. In hips with a necrosis angle of less than $200^{\circ}$, the result of osteotomy was significantly better than when the angle was larger $(\mathrm{p}<0.05)$ (Table 3).

The percentage of femoral head surface involved did not show any significant effect on the results. Radiological changes (Figs. 4 and 5) were regeneration in 2\%, stabilisation in $44 \%$, moderate deterioration in $23 \%$ and severe deterioration in $31 \%$.

\section{Complications}

Two patients had thrombophlebitis and two developed reflex sympathetic dystrophy during the period of follow-up. Fourteen hips showed delayed union of the osteotomy with one broken plate. Relationship was found between the degree of displacement and delayed union of the osteotomy.

\section{Revision operations}

Two varus osteotomies were revised to valgus because of poor progress. One of these is excluded from the series because of the death of the patient a few months after operation.

Five patients who had originally presented with Stage IV disease and one patient with Stage III involvement had total hip arthroplasties between two and three years after their original osteotomies.

\section{DISCUSSION}

In this study the overall results were acceptable but depended on the radiological staging and the necrosis angle at the time of operation.

Patients with Stage II disease before operation achieved the best scores at follow-up (91\% acceptable or better), and most were satisfied with the result of the operation.

A necrosis angle of less than $200^{\circ}$ gave significantly better results after osteotomy than did higher values. The percentage of the surface of the head of the femur involved was 
deceptive in appearance and difficult to measure because of overlying shadows. Measurement of this area was not of value in predicting the outcome of osteotomy.

Symptomatic relief of pain was achieved in all stages and it has remained within satisfactory limits, although some decrease was noted during the period of follow-up. There was slight, statistically significant, loss of movement after operation. Gait was slightly improved but this was not significant.

The radiological appearances continued to deteriorate in some hips after osteotomy in spite of revascularisation attributed to osteotomy [10]. In our view, arrest of the radiological changes is a reasonable objective for intertrochanteric osteotomy [9].

The basic correction at operation should be flexion [21, 26] combined with valgus angulation. In the early part of our series, we carried out a small number of varus osteotomies. Two of these needed revision to valgus before progress was satisfactory. Although the number of these operations is too small for valid comparison, in our experience varus osteotomy does not guarantee long-term support and conservation of the articular surface [24] in spite of the biomechanical advantages.

Although there is a precedent for lateral dis-placement of the distal fragment [3], we found no difference in knee pain six years after operation. Possibly a longer follow-up is needed. In the absence of lateral displacement other adaptation may occur if the lateral condyle is overloaded, for example, severe external rotation [1].

Osteotomy did not increase the difficulty of subsequent total hip arthroplasty [2].

We believe that the best indication for intertrochanteric osteotomy for idiopathic necrosis of the femoral head is in Ficat's Stage II, especially if the necrosis angle is less than $200^{\circ}$. No joint replacements were needed during follow-up in hips presenting at this stage. The duration of the remission justifies osteotomy in these patients. The operation should be carried out before there is collapse of the head of the femur if joint degeneration is to be avoided. The bad results in Stage IV (five revisions of osteotomies to total hips in the first three years of follow-up), lead us to advise primary joint replacement for these patients. Sugioka's osteotomy [23] might be indicated for Stage III disease, although our experience of the operation is limited and the treatment of choice remains doubtful.

\section{REFERENCES}

1. Aguilella L (1985) La osteotomia intertrocanterea en el tratamiento de la necrosis idiopatica de la cabeza del femur. Doctoral thesis, Pamplona

2. Benke GJ, Baker AS, Dohmis E (1982) Total hip replacement after upper femoral osteotomy. J Bone Joint Surg [Br] 64B: 570-571

3. Bombelli R (1976) Osteoarthritis of the hip, Pathogenesis and consequent therapy. Springer, Berlin, Heidelberg, New York

4. Bonfiglio M, Voke EM (1968) Aseptic necrosis of the femoral head and nonunion of the femoral neck. J Bone Joint Surg [Am] 50A: 48-66

5. Chacha PB (1984) Vascularised pedicular bone grafts. Int Orthop 8: 117-138 
6. Debeyre J, Goutallier D (1972) Traitement chirurgical des nécroses primitives de la tête femorale. Acta Orthop Belg 38: 546-553

7. Dixon WJ (1981) BMDP statistical software 1981. University of California Press, Berkeley, pp 1-250

8. Ficat P (1981) Early diagnosis of osteonecrosis by functional bone investigation. In: Weil UH (ed) Segmental Idiopathic Necrosis of the Femoral Head, Springer, Berlin Heidelberg New York (Progress in Orthopaedic Surgery, vol 5, pp 17-27)

9. Ficat $\mathrm{P}$ (1985) Idiopathic bone necrosis of the femoral head. Early diagnosis and treatment. J Bone Joint Surg [Br] 67B: 3-9

10. Guida G, Cigala F, Riccio V (1969) Les effets de l'ostéotomie intertrochantérienne sur la vascularisation de l'extrémité proximale du fémur. Rev Chir Orthop 55: 83-88

11. Hawkins RH, Verhelst MP, Mulier JC (1974) Idiopathic aseptic necrosis of the femoral head. Treatment by drilling and grafting. Acta Orthop Belg 40: 321-325

12. Hungerford DS (1981) Early diagnosis and treatment of ischeamic necrosis of the femoral head. In: Weil UH (ed) Segmental Idiopathic Necrosis of the Femoral Head. Springer, Berlin Heidelberg New York (Progress in Orthopaedic Surgery, vol 5, pp 29-45)

13. Imizcoz JL, Villas C, Barredo R, Cañadell J (1984) New plate for lateral translation in valgus intertrochanteric osteotomy: CUN plate. Arch Orthop Trauma Surg 103: 67-70

14. Judet H, Gilbert H, Judet J (1981) Essai de revascularisation de la tête fémorale dans les nécroses primitives et post-traumatiques. Rev Chir Orthop 67: 261-266

15. Kerboull J, Thomine J, Postel M, Merle d'Aubigné R (1974) The conservative surgical treatment of idiopathic aseptic necrosis of the femoral head. J Bone Joint Surg [Br] 56B: 291-296

16. Maquet $P$ (1972) Traitement biomécanique de la nécrose ischémique de la tête du femur. Acta Orthop Belg 38: 526-536

17. de Marneffe R (1972) Varisation dans la nécrose aseptique de la hanche. Acta Orthop Belg 38: 554-560

18. Merle d'Aubigné R, Postel M, Mazabraud A, Massias P, Gueguen J (1965) Idiopathic necrosis of the femoral head in adults. J Bone Joint Surg [Br] 47B: 612-633

19. Oriaifo A (1980) Necrosis avascular idiopática de la cabeza del fémur. Análisis de algunos posibles factores etiopatogénicos. Doctoral thesis, Pamplona

20. Pardo J, Rodriguez L, Gabarda R, Navarrete L (1982) Tratamiento de la necrosis idiopática de la cabeza femoral. Rev Orthop Traum 26-IB: 129-136

21. Simonnet JH, Aubaniac JM, Vedel F, Groulier P (1984) L'ostéotomie intertrochantérienne de flexion dans les ostéonécroses aseptiques de la tête fémoral de l'adulte. Rev Chir Orthop 70: 219-229

22. Smith K, Bonfiglio M, Montgomery W (1980) Non-traumatic necrosis of the femoral head treated with tibial bone-grafting. J Bone Joint Surg [Am] 62A: 845847

23. Sugioka Y (1978) Transtrochanteric anterior rotational osteotomy of the femoral head in the treatment of osteonecrosis affecting the hip. Clin Orthop 130: 191-201

24. Vasey HM (1984) Nécrose aseptique de la tête femorale chez le jeune adulte. Int Orthop 8: 77-88

25. Wagner H, Zeiler G (1981) Idiopathic necrosis of the femoral head. Results of intertrochanteric osteotomy and joint resurfacing In: Weil UH (ed) Segmental 
Idiopathic Necrosis of the Femoral Head. Springer, Berlin Heidelberg New York (Progress in Orthopaedic Surgery, vol 5, pp 87-116)

26. Willert HG, Buchorn G, Zichner L (1981) Results of flexion osteotomy on segmental femoral head necrosis in adults. In: Weil UH (ed) Segmental Idiopathic Necrosis of the Femoral Head. Springer, Berlin Heidelberg New York (Progress in Orthopaedic Surgery, vol 5, pp 63-80) 


\begin{tabular}{|c|c|c|c|c|c|}
\hline \multicolumn{7}{|c|}{ Table 1. Clinical result by radiological stage } \\
\hline & Bad & Acceptable & Good & Very good & Total \\
\hline II & $9 \%$ & $18 \%$ & $46 \%$ & $27 \%$ & $100 \%$ \\
\hline III & $44 \%$ & $28 \%$ & $14 \%$ & $14 \%$ & $100 \%$ \\
\hline IV & $68 \%$ & $23 \%$ & $9 \%$ & $0 \%$ & $100 \%$ \\
\hline Total & $41 \%$ & $25 \%$ & $20 \%$ & $14 \%$ & $100 \%$ \\
\hline
\end{tabular}

Table 2. Patients opinión by preoperative radiological stage

\begin{tabular}{|c|c|c|c|c|}
\hline & Unsatisfied & Satisfied & Very satisfied & Total \\
\hline II & $9 \%$ & $73 \%$ & $18 \%$ & $100 \%$ \\
\hline III & $46 \%$ & $34 \%$ & $20 \%$ & $100 \%$ \\
\hline IV & $55 \%$ & $40 \%$ & $5 \%$ & $100 \%$ \\
\hline Total & $39 \%$ & $45 \%$ & $16 \%$ & $100 \%$ \\
\hline
\end{tabular}

Table 3. Effect of necrosis angle on the result

\begin{tabular}{|c|c|c|c|c|c|}
\hline & Bad & Acceptable & Good & Very good & Total \\
\hline$<200^{\circ}$ & $31 \%$ & $16 \%$ & $28 \%$ & $25 \%$ & $100 \%$ \\
\hline$\geq 200^{\circ}$ & $48 \%$ & $29 \%$ & $14 \%$ & $9 \%$ & $100 \%$ \\
\hline Total & $41 \%$ & $25 \%$ & $20 \%$ & $14 \%$ & $100 \%$ \\
\hline
\end{tabular}




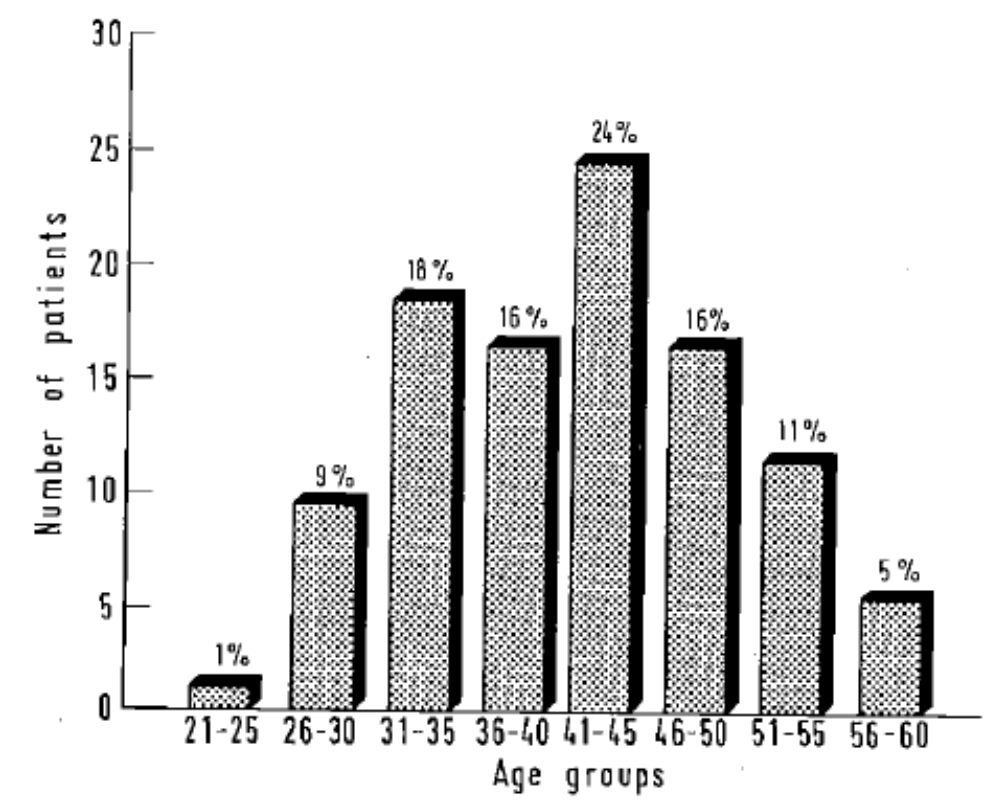

Figure 1. Age distribution by 5 year groups
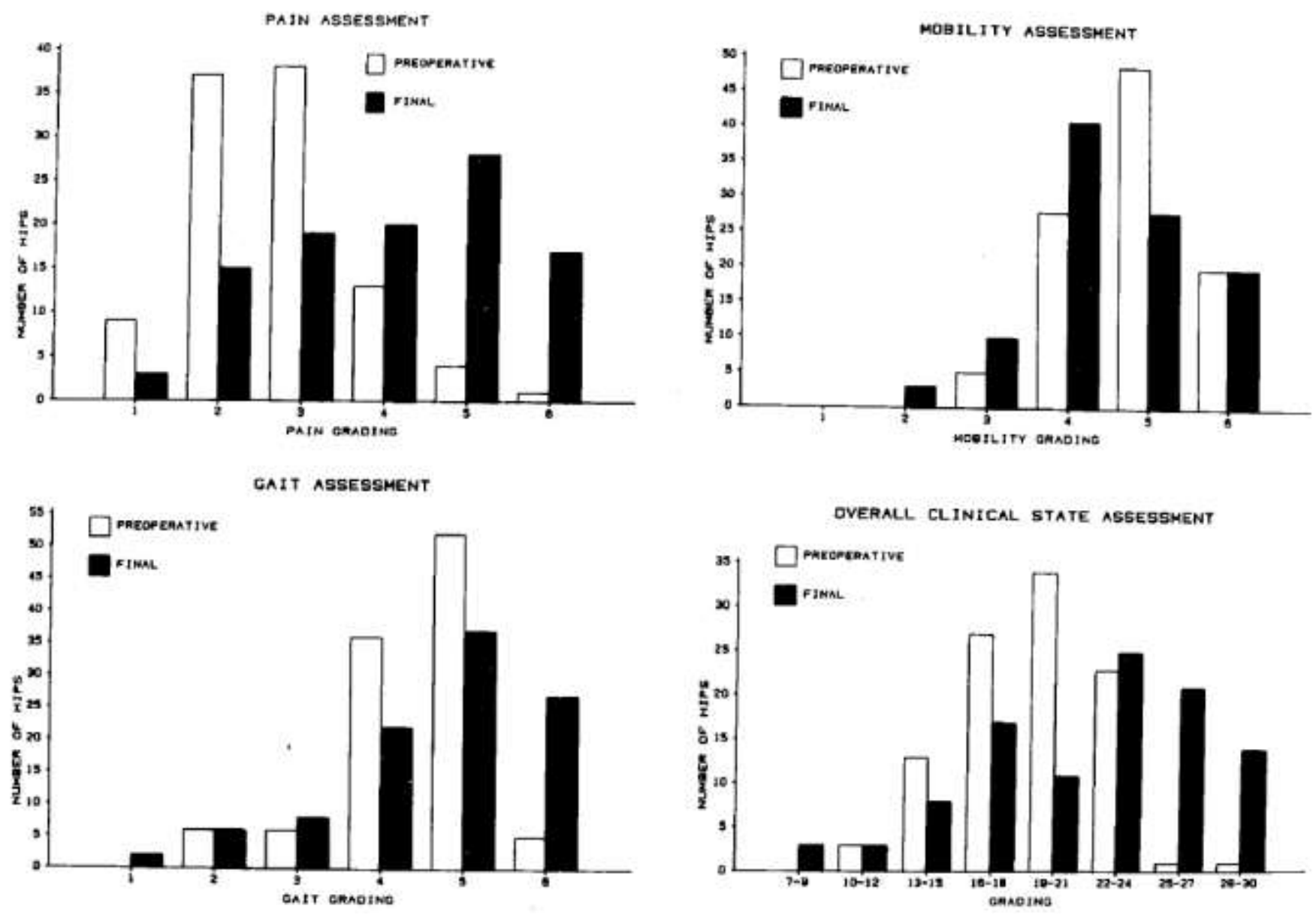

Figure 2. Preoperative and fiscal scores 


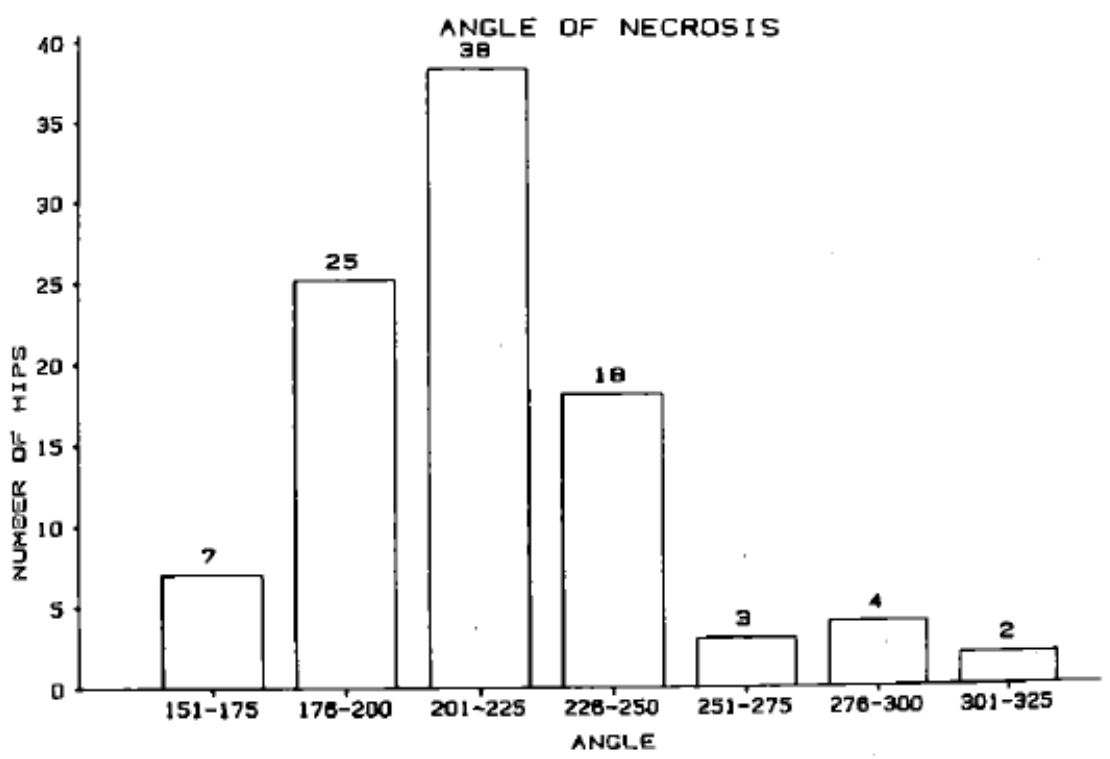

Figure 3. Distribution of the angle of necrosis
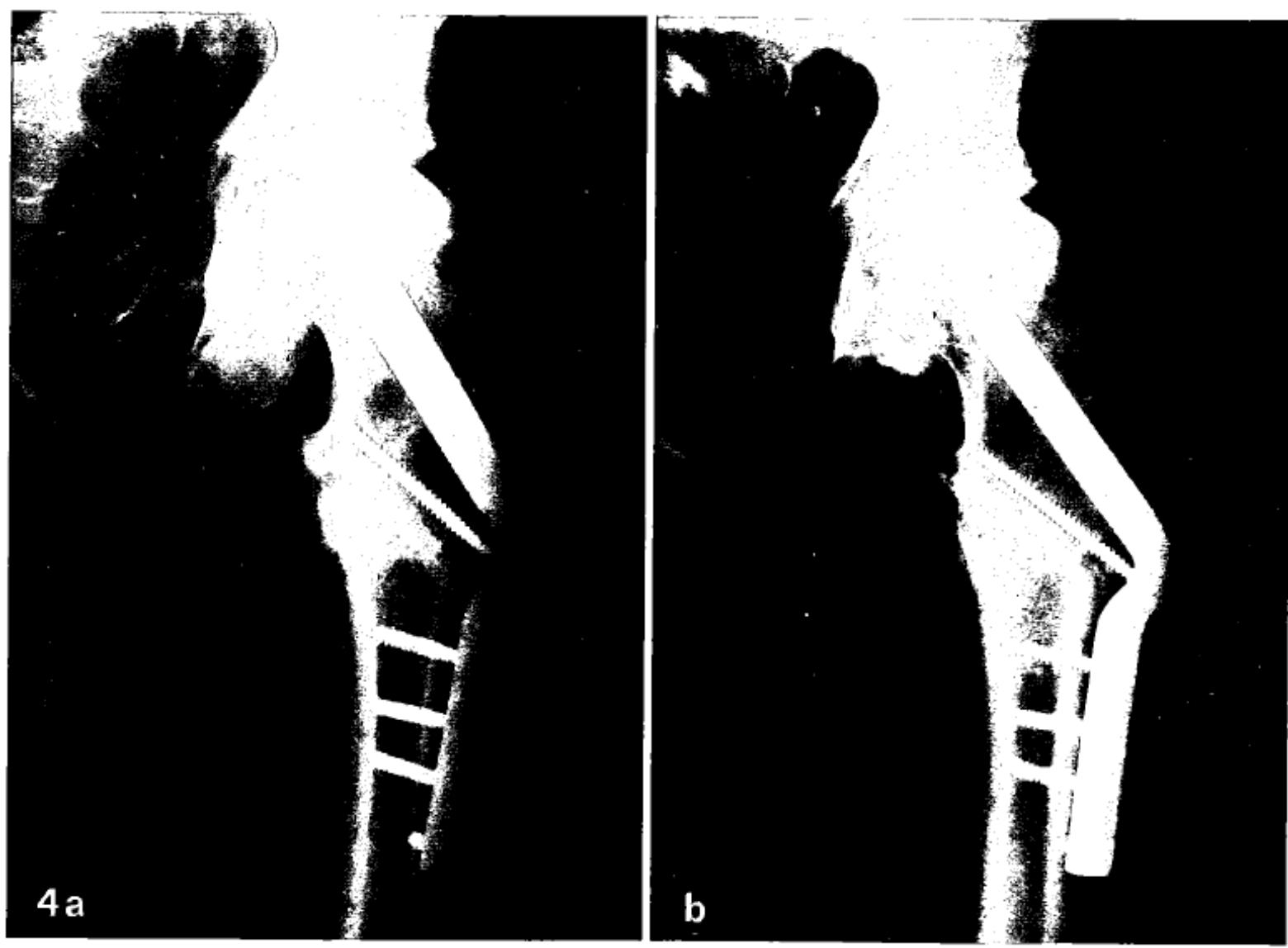

Figure 4a, b. Radiologically stable lesion. a Immediately after operation; b 5 years later 


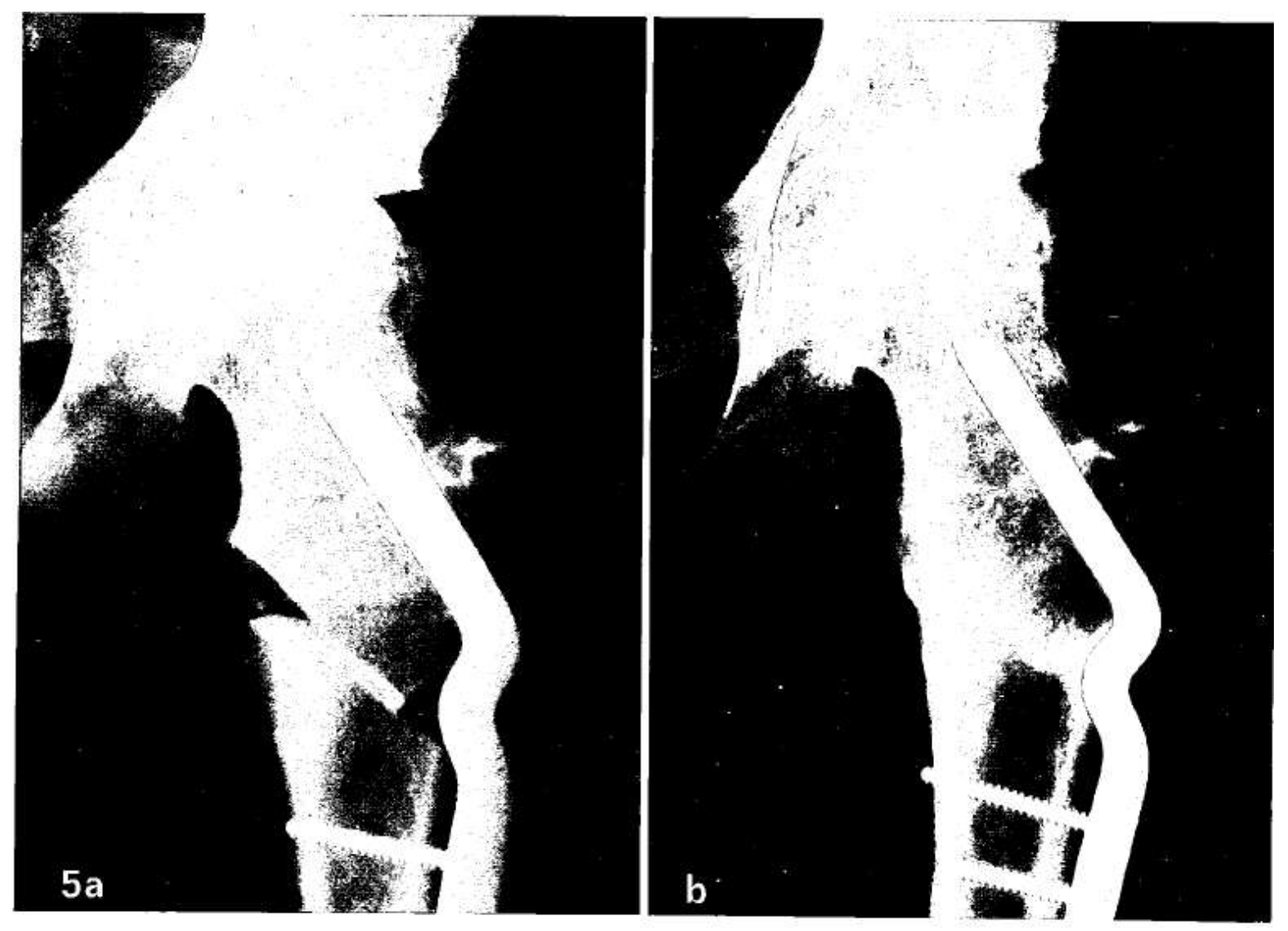

Figure 5a, b. Moderate deterioration. a Good congruence after operation; b Articular incongruence and collapse 3 years later 